\title{
Formação e papel do professor de Ciências na construção curricular: a visão dos documentos oficiais
}

Maria Nizete de Azevedo * Leonardo André Testoni **

*(UNIFESP, São Paulo, SP) Resumo: Este trabalho discute concepções de formação docente e o papel do professor diante do currículo prescrito, **(UNIFESP, São Paulo, SP) a partir da visão de documentos curriculares da área de Ciências de seis estados brasileiros. A análise foi mediada por categorias elaboradas com base nos modelos de formação docente (racionalidade técnica, epistemologia da prática e da crítica) e nos papéis que podem ser assumidos pelo professor: manutenção-imitação, mediador curricular e criativo-gerador (SACRISTÁN, 1991). Resultados indicam a coexistência dos modelos técnico e prático e tímidos indícios do crítico, com predomínio para a formação do professor prático, coerente com a previsão mais acentuada do professor como mediador curricular. Conclui-se que esses resultados significam avanços representativos de possíveis mudanças em prol da formação do professor reflexivo/ crítico e da construção da docência como práxis.

Palavras-chave: Formação de professores. Modelos formativos. Papel docente. Orientações curriculares. 
INTRODUÇÃO

A intenção deste trabalho é discutir sobre as concepções de formação de professores e o papel docente na construção e/ou implementação curricular no contínuo da atividade profissional a partir da visão apresentada por documentos curriculares de seis estados brasileiros (PE, AC, AL, MT, SP, $P R)$. Este artigo originou-se da pesquisa intitulada "Currículos para os anos finais do ensino fundamental: concepções, modos de implantação e usos", realizada pelo Centro de Estudos e Pesquisas em Educação, Cultura e Ação Comunitária (Cenpec) com apoio da área de Estudos \& Pesquisas da Fundação Victor Civita (FVC), da qual a primeira autora participou como consultora na análise dos documentos curriculares em Ciências.

O termo DoCUMENTo é aqui adotado, tal como foi definido pelo Cenpec, como o "[...] conjunto de materiais analisados em cada unidade da federação, em sua maior parte compostos pela apresentação de concepções, resoluções, fundamentos e 'conteúdos' de disciplinas” (Roteiro para guiar a análise dos especialistas, Cenpec, 2014).

A temática sobre a formação de professores foi escolhida entre outras possíveis por ser considerada de grande relevância no campo das pesquisas em ensino de Ciências. No âmbito da discussão sobre a reconhecida crise que acomete o ensino de modo geral, a formação contínua é vista como uma das possibilidades de se buscarem caminhos de superação.

Diante do rápido avanço científico e tecnológico e das subsequentes mudanças de cunho social, político, cultural e pedagógico, a contínua formação para o professor de ciências torna-se imprescindível. Nesse sentido, garantir a permanência dessa formação e buscar melhorias para o ensino têm sido interesse de muitos dos programas educacionais implantados nas redes oficiais, realizados por meio de diferentes modelos de formação.

Esses modelos se diferenciam principalmente no modo como o professor é concebido e no seu papel na construção de sua identidade e autonomia como profissional. Esse é o motivo porque vinculamos, no foco da discussão aqui proposta, a formação do professor e o seu papel na construção e/ou implementação do currículo preestabelecido.

Com a discussão aqui proposta não pretendemos fazer juízo de valor às concepções de formação inerentes aos documentos curriculares, mas discutilas à luz da literatura na área de pesquisas em formação de professores. 
Pretendemos, unicamente, contribuir com reflexões que possam propiciar avanços na construção de modelos formativos coerentes com necessidades formativas dos professores em sua atuação profissional.

MOdELOS DE FORMAÇÃO DOCENTE E O PAPEL DOCENTE NA CONSTRUÇÃO CURRICULAR: ELEMENTOS TEÓRICOS

\section{A racionalidade técnica}

Diferentes pesquisas (MARANDINO, 2003; PÉREZ GÓMES, 2000; AZEVEDO, 2013; DUARTE et al., 2009) indicam o predomínio do modelo de formação pautado na racionalidade instrumental e técnica. No âmbito desse modelo, a prática docente é vista como a solução instrumental de problemas mediante a aplicação de um conhecimento teórico previamente transmitido (e disponível) que provém da pesquisa científica pura nos campos específicos e nas ciências de educação. Para Contreras (2002, p. 91), essa prática ou papel do professor estaria delimitada pela “[...] aplicação de técnicas e procedimentos que se justificam por sua capacidade para conseguir os efeitos ou resultados desejados".

Como exposto em Testoni e Abib (2014), no modelo de professor como profissional técnico, os fins do processo são extremamente bem fixados e definidos, o que infere a atuação docente como um aplicador de procedimentos, regras e meios técnicos visando a obtenção dos resultados almejados por meio da prática profissional acrítica.

Azevedo (2013) corrobora com essa discussão ao explicitar que no modelo da racionalidade técnica há certo controle sobre a atuação docente, seja por meio de prescrições curriculares, seja por meio de processos formativos que privilegiam a repetição de práticas pensadas e elaboradas por outros especialistas. Esse controle resulta em uma explícita dicotomia pesquisadortécnico, conceber-fazer, em que o docente não apresenta habilidades nem é formado para a elaboração dos processos realizados, mas apenas para sua aplicação.

Villani \& Freitas (2002), entre outros estudos, presumem a perpetuação da abordagem tradicional para o ensino pautado na transmissão-recepção de informações (MIZUKAMI, 1986) como uma das consequências desse modelo formativo. 0 professor formado nesse viés e inserido em processos formativos que não superam tal concepção, mas ao contrário, a reforçam, tende a continuar com a repetição, com a desarticulação entre as áreas de seu próprio 
conhecimento e da cultura em geral. Esses autores atribuem a esse modelo dificuldades e resistências a mudanças no ensino, possivelmente explicadas pela falta de consideração de aspectos importantes ao processo formativo, os saberes docentes, suas experiências e contextos de atuação.

Epistemologia da prática - Professor reflexivo

O modelo da epistemologia da prática ou da racionalidade prática segue 0 curso contrário ao da técnica por valorizar não apenas os conhecimentos dos professores, mas a reflexão como a base que sustenta a formação docente. A discussão sobre $o$ ato de refletir no âmbito da formação de professores foi inaugurada por John Dewey (RODRIGUES, 2001), mas o autor de destaque nessa concepção é Donald Schön por ser considerado o difusor do conceito professor reflexivo.

Segundo SCHÖN (1992), a prática profissional do professor reflexivo reúne dois momentos gerais: (a) o conhecimento-na-ação, que engloba todas as ações docentes realizadas espontaneamente, seja por sua simplicidade, seja por sua repetição durante a carreira; e (b) a reflexão-na-ação, que trata das situações não rotineiras, em que é necessário pensar sobre o que fazemos durante a ação. A proposta prevê que a reflexão propiciará que tal situação problemática componha o repertório do profissional, provavelmente transformando-se em conhecimento-na-ação na próxima vez que ocorrer um caso similar.

Duarte et al. (2009) explicitam que na abrangência dessa concepção “[...] o processo de formação se dá por meio de uma conversação reflexiva” (p. 4), cuja intenção não é senão a superação da dicotomia entre meios e fins, entre conhecer/planejar-fazer, aparente na racionalidade instrumental e técnica.

Vale ressaltar que no viés próprio deste modelo, a prática não se abre para a resolução de problemas com determinados fins, mas também à reflexão de quais devem ser os fins a serem estipulados. Portanto, a prática reflexiva se encaixa mal em contextos de burocratização e controle, em que as metas se encontram previamente definidas à margem dos problemas concretos e reais enfrentados pelos professores. Em geral, os problemas que demandam atitudes reflexivas dos profissionais são aqueles para os quais não são válidas as soluções acumuladas, iniciando a espiral "avaliação - ação - nova avaliação" (SCHÖN, 1992, p. 132).

Os pressupostos defendidos por Schön foram valorizados como contribuições no campo das reformas curriculares e considerados como avanços em relação aos modelos formativos pautados na racionalidade técnica. Para Abib (2010), 
o reconhecimento dos limites do modelo instrumental para o profícuo desenvolvimento profissional docente gerou a defesa da epistemologia da prática. Na abrangência da concepção que sustenta esse modelo, as reflexões dos professores sobre seu trabalho constituem o cerne dos processos de geração dos conhecimentos profissionais, o que sugere um processo de investigação permanente sobre suas próprias ações na sala de aula.

Testoni e Abib (2014) expõem que o professor como indivíduo reflexivo deve guiar-se pelos valores educativos pessoalmente assumidos, negociar e equilibrar os interesses de cunho social e político, além de se predispor a pesquisas e reflexões sobre sua prática (deliberando na incerteza acerca da forma moral ou educativamente correta de agir em cada caso). Tal quadro permite inferir que o docente apresenta uma autonomia no tocante à responsabilidade moral individual, considerando os diferentes pontos de vista. Além disso, caracteriza-se, aqui, um docente com capacidade para resolver situações-problema apresentadas pelo cotidiano da sala de aula, com realizações práticas das pretensões educativas.

Todavia, a despeito do avanço da epistemologia da prática em relação à racionalidade técnica, pesquisas sobre a formação do professor reflexivo, realizadas a partir da problematização do contexto escolar e dos tantos fatores que influenciam a prática docente no dia a dia da escola, resultaram em análises críticas sobre as ideias de Schön e, por suposto, sobre os pilares que sustentam a formação docente orientada por modelos práticos.

Pimenta (2002), Contreras (2002) e Ghedin (2002) são alguns desses pesquisadores que analisam criticamente os pressupostos schönianos, com propostas de ampliação. Pimenta (2002) destaca a insuficiência do conhecimento prático mobilizador das ações cotidianas do professor, o qual não se aplica na resolução de situações novas e ou conflituosas. Para essa autora, o limite dessas compreensões pode ser em decorrência da falta de teorização sobre a análise e reflexões, realizadas não apenas sobre a atuação imediata, mas, sobretudo, para visualizar e entender as reformas e imposições advindas das instituições no cenário político educacional. Outro aspecto que também pode limitar o conteúdo da reflexão docente é o fechamento do professor em sua sala de aula, isolado dos contextos sociais, políticos e econômicos que circundam o ambiente e a comunidade escolar.

Novas visões são oriundas desse cenário de críticas, com destaque para a formação do intelectual crítico e para a formação do professor numa perspectiva reflexiva e crítica, sintetizada nos pressupostos da epistemologia da práxis. 
A concepção do professor como um intelectual crítico e reflexivo é entendida como um movimento que parte da epistemologia da prática à construção e prática da epistemologia da práxis ou epistemologia da crítica. Nesse movimento, forma-se um “[...] profissional que dá sentido e significado ao seu fazer num dado contexto histórico" (GHEDIN, 2002, p. 130). Desse modo, a reflexão, tal como é pressuposta por Schön, dá lugar à reflexão crítica orientada por elementos teóricos em um processo de transformação da prática pedagógica em direção à emancipação crítica. A práxis pedagógica assentase sobre a inseparabilidade entre a teoria e a prática, sobre a associação entre a concepção e a ação, essência, por assim dizer, da identidade humana.

Defende-se por meio dessas concepções que o professor tome consciência não apenas do papel político e social da escola na busca por garantir o acesso ao conhecimento historicamente produzido pela humanidade (SAVIANI, 2003), mas também da necessidade de se constituir como um sujeito com autonomia sobre o currículo e sobre suas ações. Autonomia para escolher o que ensinar e decidir quais são os melhores métodos de aprendizagem para seus alunos.

Para Ghedin (2002, p. 129), “[...] é preciso transpor o modelo prático-reflexivo para uma prática dialética, que compreenda as razões de sua ação social”. Para o autor, a reflexão crítica docente emana da participação no contexto de aprendizagem, envolvendo, inclusive, os aspectos econômicos e políticos que ultrapassam o espaço restrito da sala de aula.

Em suma, a necessária e difícil formação do professor reflexivo-crítico acontece em um processo e, por isso, cresce gradativamente. Não se é reflexivo crítico porque se deseja ou porque se decide sê-lo. Há, acima de tudo, a necessidade de se organizar em coletivo, para que se criem condições de análise, reflexões e proposições diante de situações apresentadas em contextos diferenciados, a destacar o contexto de reformas curriculares. Busca-se para além do professor crítico reflexivo, almeja-se, como já disse Alarcão (2005), a escola reflexiva, como um organismo vivo, pulsante, composto por docentes capazes de escolher e traçar seus próprios caminhos. 


\section{CURRÍCULO E PAPEL DOCENTE: ALGUNS POSICIONAMENTOS}

Esclarecemos que ao nos referirmos ao papel docente na construção curricular, assumimos o pressuposto de que currículo não se trata apenas do conjunto de orientações que chegam às mãos do professor. Esse conjunto de orientações ou documentos situa-se no plano do "currículo prescrito", tal como define José Gimeno Sacristán (2000, p. 138): um “compêndio” de orientações e “conteúdos ordenados", proposto pelos órgãos políticos e administrativos. Trata-se também do currículo "concreto e real” compreendido como “[...] um âmbito de interação no qual se entrecruzam processos, agentes e âmbitos diversos que, num verdadeiro e complexo processo social, dão significado prático e real ao mesmo" (SACRISTÁN, 2000, p. 129).

Interpreta-se "âmbito de interação" como a inter-relação de inúmeras práticas e relações sociais ocorridas nos contextos internos e externos à escola, bem como o que se faz dentro e fora da sala de aula em prol do ensino e da aprendizagem. Essas relações, ainda que tenham dinâmicas próprias, são influenciadas por fatores políticos, sociais e culturais, os quais, por sua vez, influenciam as atividades dos diferentes sujeitos do ambiente escolar.

Segundo Canavarro e Ponte (2005), o papel do professor diante de um currículo preestabelecido ou diante da construção curricular pode ir desde a passividade e execução ao papel de criticidade e autonomia na busca de soluções para problemas que demandam de sua atividade pedagógica.

José Gimeno Sacristán (1991) delimita esse papel com mais precisão. Para esse autor, o professor pode assumir três níveis diferenciados de papéis diante do currículo, a depender do seu grau de independência profissional: o primeiro nível seria imitação-manutenção, relacionado aos pressupostos definidos como racionalidade técnica, cujo papel docente esperado seria o de reproduzir as imposições dos guias e manuais curriculares, sem crítica; o segundo nível seria o da mediação, o qual prevê um papel no âmbito da prática, que seria interpretar, adequar, adaptar e ajustar as inovações e proposições curriculares à realidade da escola; o terceiro nível prevê o professor criativogerador, com autoria curricular, o qual, junto com outros professores, são sujeitos de suas ações, e como tais, responsável pelo processo de ensino, desde a escolha de conteúdos e planejamentos à avaliação e replanejamento de sua prática.

O nosso entendimento é de que documentos curriculares, embora componham o currículo prescrito, podem conter orientações que incentivem e mobilizem 
professores e demais atores da escola à construção do "currículo concreto e real”, com ênfase para o desenvolvimento de uma autonomia curricular na altura do professor crítico e reflexivo. O sentido adotado para o conceito de autonomia curricular é o mesmo que lhe é atribuído por Morgado (2011, p. 799):

[...] como uma oportunidade de mobilizar os agentes e as estruturas locais em torno do fenómeno educativo, o que implica ampliar os seus poderes de decisão, a autonomia é um meio de reforçar o papel da escola e de envolver os professores na contextualização, modelação e enriquecimento do currículo proposto a nivel nacional, isto é, na (re) construção do currículo que desenvolvem.

A partir desses pressupostos justificamos nossa pergunta: quais papéis são delegados aos professores pelos documentos analisados?

\section{MÉTOdo}

A pesquisa realizada foi guiada por um instrumento roteiro preenchido a partir da análise das orientações curriculares de cada estado (PE, AC, PR, AL, MT, SP). Não faremos menção aos documento do estado de Alagoas, por este não ser dirigido especificamente à área de Ciências. Para a presente discussão, extraímos dados das respostas contidas no instrumento roteiro, revisitando os documentos originais para complementação. Elegemos para análise apenas as questões/respostas que dizem respeito ao foco em debate, a saber: Bloco 1: Conteúdos de ensino e aprendizagem - 1.90 documento prevê algum papel para a escola na seleção ou adaptação de "conteúdos"?; Bloco 2: Fundamentos teóricos - 2.30 documento sugere uma bibliografia de referência para a formação do professor?; Bloco 3: Didatização e implementação - 3.1 Há sugestões (exemplos, indicações gerais) sobre como devem se dar os processos didáticos para o ensino do "conteúdo" da disciplina analisada?; 3.2 Há indicações exaustivas e sequenciadas de atividades de ensino, materiais didáticos, como cadernos de aprendizagem para o professor e para o aluno?; 3.40 documento apresenta orientações para a formação de docentes da disciplina?

Reforçamos que a abordagem sobre o papel do professor na construção/ implementação curricular não se refere à pesquisa realizada diretamente na escola, mas limita-se às previsões contidas nos documentos. Esse esclarecimento estende-se para a formação docente, também abordada a partir de inferências sobre as orientações dirigidas ao modo como se concebe a formação, explícitas em alguns documentos e implícitas em outros.

A análise e discussão proposta são orientadas pela premissa de que a atuação 
docente prevista em um documento curricular está diretamente relacionada ao modo como esse profissional é concebido e ao modo como se projeta a sua formação. Enfim, a discussão será guiada por dois eixos indicadores: 1. A racionalidade técnica com aproximações à epistemologia da prática: da imitação à mediação do currículo; 2. Epistemologia da prática com indícios da epistemologia crítica: da mediação do currículo à autonomia curricular.

\section{DISCUSSÕES E RESULTADOS}

A racionalidade técnica com aproximações à epistemologia da prática: da imitação à mediação do currículo

Embora muitas pesquisas sobre a formação de professores de Ciências indiquem a necessidade de se formar professores com formação teórica e prática que lhes possibilitem a construção da práxis pedagógica, entre os documentos analisados nos quais as concepções são explicitadas, encontramos posicionamentos que oscilam entre elementos característicos da racionalidade técnica e da epistemologia da prática, alguns com tímidos indícios situados no plano da epistemologia da práxis.

Essa interpretação guarda coerência com a concepção manifestada nas orientações curriculares do estado de Pernambuco. Vale destacar que os documentos desse estado primam pela formação e atuação em sala de aula ao criar seus próprios parâmetros, um dirigido à formação para o ensino de Ciências e outro à sala de aula. Sem dúvida, esse é um diferencial em relação aos demais documentos. 0 documento em destaque expressa as intenções do programa de formação do professor de Ciências por meio da seguinte orientação teórico-pedagógica:

Instrumentalizar os professores para a elaboração de planejamentos de ensino e sequências didáticas para o ensino de Ciências Naturais, tendo como referência os conceitos de Competência, Habilidade, Expectativa de Aprendizagem, Estratégias de Ensino e Currículo; promover reflexões acerca dos modos de conceber o ensino, de definir metas para a aprendizagem e de planejar as fases de uma sequência didática; estimular o posicionamento crítico dos professores frente aos planejamentos e atividades didáticas cotidianamente desenvolvidas nas aulas de Ciências; auxiliar os professores na identificação de quais expectativas de aprendizagem estão efetivamente sendo trabalhadas nas diferentes atividades pedagógicas propostas para o ensino de Ciências da Natureza; atualizar os professores nas concepções teóricas mais contemporâneas acerca da Organização Curricular, para o alcance das competências previstas para o Ensino Fundamental, nos anos iniciais e finais; estimular e criar formas de capacitar os professores no uso de diferentes tecnologias; promover reflexões acerca da importância da relação teoria/prática no Ensino de Ciências (PERNAMBUCO, 2014, p. 48). 
No âmbito dessa orientação, constata-se a coexistência dos modelos técnicos e práticos, embora se considere a tônica impregnada no verbo que inicia a frase - instrumentalizar. Sem dúvida, não se trata de qualquer verbo, sobretudo ao se referir a um corpo de intenções a respeito da formação de professores. Entretanto, a instrumentalização proposta é direcionada para a intenção de elaboração e planejamento, o que atenua a conotação da racionalidade técnica e aproxima essa orientação do campo da epistemologia da prática. Outros elementos acusam essa aproximação, como a intenção de promover reflexões, estimular o posicionamento crítico, além de pautar a importância da relação teoria e prática no ensino de Ciências.

Por outro lado, o campo da racionalidade técnica se faz presente com a referência ao conceito de competência, analisado e criticado por pesquisadores que voltam seus estudos para a formação de professores. Segundo Pimenta (2002), no campo da educação, mais precisamente na abrangência da formação docente, o conceito de competência vem substituindo o de saberes e conhecimentos. Para essa autora, esse debate não se trata “[...] de mera questão conceitual”. Essa posição é justificada:

Competências, no lugar de saberes profissionais, deslocam do trabalhador para o local de trabalho a sua identidade, ficando este vulnerável à avaliação e controle de suas competências, definidas pelo "posto de trabalho". Se estas não se ajustam ao esperado, facilmente poderá ser descartado (PIMENTA, 2002, p. 42).

Pimenta afirma que esse discurso também se aplica à docência, pois professores podem estar sendo preparados para a execução de tarefas definidas sob interesses e necessidades alheios aos seus como profissionais. Nesse sentido, a autora persiste na associação do conceito de competência ao modelo da racionalidade técnica, sobretudo se comparado ao conceito de conhecimento. Em suas palavras:

[...] ter competência é diferente de ter conhecimento e informação sobre o trabalho, sobre aquilo que se faz (visão de totalidade; consciência ampla das raízes, dos desdobramentos e implicações do que se faz para além da situação; das origens; dos porquês e para quê)

(PIMENTA, 2002, p. 42).

Capacitação é outro conceito que também chama a nossa atenção. A intenção de "criar formas de capacitar os professores", embora se refira ao uso de inovações tecnológicas, o que minimiza o teor de treinamento a si relacionado, também vincula o modelo formativo proposto com a racionalidade técnica na formação docente. 0 termo capacitação é constantemente associado à repetição de ações preconcebidas por outros, à “[...] elaboração de pacotes educacionais e propostas descontextualizadas sem a participação dos 
professores, supondo uma aceitação acrítica dessas propostas” (ARRUDA, 2004, p. 32).

As orientações contidas nos "Parâmetros de Formação Docente para o Ensino de Ciências Naturais" do Programa de Formação previsto para a rede do estado de Pernambuco, se visualizada sob esse viés teórico, propõe para o professor uma formação técnica com aproximações à epistemologia da prática, por coexistirem em suas orientações conceitos como instrumentalização, reflexão, competência, capacitação e relação teoria-prática.

Essa coexistência de modelos é coerente com o papel previsto para o professor em sua atuação na escola diante do currículo proposto por esse estado. Esse papel está explicitado nos Parâmetros na sala de aula Ciências Naturais 6으 ao 9ำ ano do Ensino Fundamental, tal como é pontuado no roteiro adotado para guiar as análises:

\begin{abstract}
No corpo desse documento, encontramos sugestões de atividades de ensino com minúcias para as orientações de como executá-las. Essas orientações abrangem os passos metodológicos, expectativas de aprendizagem a serem alcançadas com a aplicação das mesmas e sugestões e dicas para a condução de cada etapa da atividade. Essas dicas e sugestões aparecem em balões de diálogos, por meio dos quais se estabelece a comunicação com o professor. Textos científicos/informativos também são propostos no corpo da atividade, os quais subsidiariam o professor e os estudantes (PERNAMBUCO, 2014).
\end{abstract}

Interpreta-se, a partir do detalhamento das orientações, determinado nível de racionalidade técnica apoiada sobre o papel que se espera do professor na escola - o de imitação e manutenção das atividades sugeridas. Entretanto, o próprio documento trata de rever essa conotação, ao ter o cuidado de chamar a atenção para a importância do professor na adequação, ampliação e condução das atividades na amplitude do modelo de professor mediador do currículo. Vejamos o que revela o documento:

\footnotetext{
É importante lembrar que os exemplos de atividades não esgotam as inúmeras possibilidades de trabalho com cada tema do eixo escolhido [...]. Você [professor] é quem decidirá, baseado em sua experiência, o momento mais adequado para o uso de cada atividade didática que aqui apresentamos (PERNAMBUCO, 2013b, p. 15).
}

Enfim, o que apresentamos aqui são apenas alguns exemplos dentro da infinidade de possibilidades existentes. Cabe ao professor adequar, ampliar, construir novas propostas a partir das referências e conduzi-las da maneira que lhe for mais conveniente, levando em consideração o público-alvo, a realidade escolar, o contexto socioambiental e cultural da sua região, especialmente tendo em vista alcançar as expectativas de aprendizagem previstas para cada temática (PERNAMBUCO, 2013b, p. 17). 
A conotação de manutenção e imitação foi abrandada, embora permaneça a aparência de controle sobre as ações docentes. Mesmo a adequação, a ampliação e até a construção de novas propostas, ainda que conduzidas "da maneira que lhe for conveniente", deverão ocorrer "a partir das referências". 0 instrumento de controle seriam, portanto, as "referências" e a meta de “alcançar as expectativas de aprendizagem prevista para cada temática”.

O papel do professor como mediador curricular também está previsto nos documentos do estado do Acre. Os papéis da escola e dos professores são baseados nos níveis de concretização previstos nos Parâmetros Curriculares Nacionais (PCNs):

O quarto nivel de concretização curricular é o momento da realização da programação das atividades de ensino e aprendizagem na sala de aula. É quando o professor, segundo as metas estabelecidas na fase de concretização anterior, [Os Parâmetros Curriculares Nacionais e as propostas das Secretarias] faz sua programação, adequando-a àquele grupo específico de alunos (ACRE, 2010, p. 7).

O documento do estado do Acre não explicita orientações para a formação docente, as quais são inferidas a partir do papel que se espera para o professor diante do currículo prescrito. Nesse sentido, infere-se pela coexistência dos modelos técnico e prático, por preconceber a um só tempo o controle sobre a programação de ações pelo professor e a permissão para que essa programação seja feita por esse profissional.

O documento do estado de São Paulo também enfatiza o papel de adaptação na implementação do currículo na escola. Entretanto, a indicação de cadernos de aprendizagem para o estudante com cópia para o professor tonifica a possibilidade da racionalidade técnica como modelo concebido para a formação e orientação para a atuação docente. Com os cadernos em suas mãos, o papel do professor seria o de “[...] adaptar as sequências didáticas contidas neste material à real necessidade de cada sala de aula, considerando o ritmo de aprendizagem de cada aluno e suas especificidades [...]" (SÃO PAULO, 2014/2017, p. 5).

Epistemologia da prática com indícios da epistemologia crítica: da mediação do currículo à autonomia curricular

As concepções sobre a formação de professores contempladas nas diretrizes curriculares do estado do Paraná aproximam-se mais da epistemologia prática com indícios da epistemologia da crítica. Delimita que a formação continuada deve ser "[...] focada nos aspectos fundamentais do trabalho educativo [...]", por meio da qual se pretende "[...] recuperar a função da escola pública paranaense que é ensinar, dar acesso ao conhecimento [...]” (PARANÁ, 2008, p. 7). 
A vinculação do foco da formação a elementos oriundos do trabalho educativo, a pretensão de recuperar a função social da escola, bem como o fato de assumir que a função da escola é o acesso ao conhecimento distanciam a concepção sobre formação docente da racionalidade técnica e a aproximam das epistemologias da prática e da crítica. O conteúdo dessas intenções consta de elementos teóricos respaldados na Pedagogia Histórico-Crítica ou teorias críticas, tal como o próprio documento adota.

Demerval Saviani é um dos defensores da Pedagogia Histórico-Crítica, para quem "O trabalho educativo é o ato de produzir, direta e intencionalmente, em cada indivíduo singular, a humanidade que é produzida histórica e coletivamente pelo conjunto dos homens" (SAVIANI, 2003, p. 13). Em tal perspectiva, o professor desempenharia o papel de organizar e sistematizar o conhecimento em sua prática pedagógica de modo que este fosse acessível ao aluno, o que é coerente com o destaque desse autor sobre o acesso ao conhecimento, como função social da escola.

\section{[...] a escola existe, pois, para propiciar a aquisição dos instrumentos que possibilitam o acesso ao saber elaborado (ciência), bem como o próprio acesso aos rudimentos desse saber (SAVIANI, 2003, p. 15).}

De fato, a importância delegada pela diretriz do estado do Paraná à formação continuada está direcionada à intenção de resolver possíveis insuficiências docentes no que diz respeito à função social da escola:

\section{Dificuldades na formação inicial ou a carência de formação continuada do professor podem tornar-se obstáculos ao processo de ensino-aprendizagem, pois a falta de fundamentação teórico-metodológica dificulta uma seleção coerente de conteúdos, bem como um trabalho crítico-analítico com o livro didático adotado (PARANÁ, 2008, p. 60).}

Essas diretrizes, além de se apoiarem nas teorias críticas, também se pautam em autores teoricamente relacionados à linha inserida no campo do socioconstrutivismo (CARVALHO; GIL-PÉREZ, 2001) para orientar sobre seus entendimentos acerca das necessidades formativas do professor de Ciências em contínuo processo de formação. Para ensinar Ciências é necessário que o professor tenha conhecimento sobre: a história da ciência, métodos científicos empregados na produção de conhecimentos, relações conceituais, interdisciplinares e contextuais associadas à produção de conhecimentos e sobre desenvolvimentos científicos recentes, questões sociais e ambientais, além de "saber selecionar conteúdos científicos escolares adequados ao ensino, considerando o nível de desenvolvimento cognitivo dos estudantes e o aprofundamento conceitual necessário" (PARANÁ, 2008, p. 61). 
Entretanto, embora se aproximem das teorias críticas, ao orientarem a formação docente, não guardam coerência com os pressupostos dessa concepção ao limitarem a autonomia e a responsabilidade do professor diante do currículo prescrito. Asseguram o controle sobre a atuação docente ao negarem a possibilidade de supressão de conteúdos que compõem a base curricular mínima proposta. Fecham as portas para o professor criativogerador, mas abrem espaço para que o professor atue como mediador curricular ao lhe autorizar selecionar e até acrescentar conteúdos específicos, com possibilidades também de optar por abordagens, estratégias e recursos.

Por serem conhecimentos fundamentais para a série, não podem ser suprimidos nem reduzidos, porém, o professor poderá acrescentar outros conteúdos básicos na proposta pedagógica, de modo a enriquecer o trabalho de sua disciplina naquilo que a constitui como conhecimento especializado e sistematizado (PARANÁ, 2008, p. 83).

As orientações do estado de Mato Grosso aproximam-se um pouco mais da autonomia curricular e do professor concebido como criativo-gerador, pois lhe são delegadas a construção e a reorganização curricular. Todavia, essa criatividade é também limitada, pois, como consta no documento, deve ser assentada sobre os subsídios fornecidos e sobre a necessidade de inclusão dos estudantes no processo de ensino e aprendizagem (MATO GROSSO, 2010, p. 32).

Em suma, a despeito de qual concepção orienta a formação do professor na escola e de qual papel se espera que ele desempenhe diante das diretrizes postas em suas mãos, é consensual, no corpo das orientações analisadas, a ideia de que o professor é quem põe o currículo em prática, seja para mantêlo, adaptá-lo ou construí-lo.

Essa ideia também é consensual entre pesquisadores, com o acréscimo da ressalva de que o papel de manutenção-imitação é insustentável diante do novo quadro de conhecimentos e necessidades que se abre ao profissional docente (CANAVARRO; PONTE, 2005). Para esses autores, intenções prescritas nessa direção, mesmo sobre controle efetivo, não se concretizam na prática, pois podem ser alteradas ou não assumidas pelos professores.

Talvez seja em respeito a considerações como essas que sobressai entre as orientações a concepção do professor na epistemologia prática - aquele de quem se espera o papel de mediador do currículo, que atua muito bem adaptando, adequando, escolhendo e decidindo sobre as opções oferecidas. 


\section{CONSIDERAÇÕES FINAIS}

Para finalizar, retomamos o propósito deste artigo em discutir, com base nos documentos curriculares, as concepções de formação docente e o papel do professor na construção curricular.

Reafirmamos a constatação de que nenhum dos documentos concebe a formação docente por um único modelo formativo. Verifica-se uma mescla de concepções, ora pendendo para a instrumentalização, ora para a prática, com poucos indícios de posicionamentos comprometidos com a epistemologia da práxis fundamentada no âmbito das teorias críticas.

Sem dúvida, é possível inferir pelo privilégio da prática, sobretudo se tomarmos como referência a discussão sobre a previsão de qual papel o professor deve assumir diante dos documentos que caem em suas mãos. Sobressai a visão do professor mediador curricular, ao the ser delegada a possibilidade de adaptar, adequar, ampliar, selecionar e decidir sobre conteúdos e estratégias de ensino. 0 professor criativo-gerador marca tímida presença apenas no documento do estado de Mato Grosso, com a orientação que possibilita a esse profissional a construção e reorganização curricular.

É comum às orientações, mesmo àquelas que se aproximam da epistemologia da crítica, a função de controle exercida pelo documento sobre os rumos que a prática do currículo pode tomar na escola. Qualquer abertura que por ventura levasse à autonomia curricular esbarraria nas paredes do prescrito. 0 limite máximo para a autoria e responsabilidade do professor diante da construção do currículo é o acréscimo de conteúdos. Ainda que não se constate uma racionalidade técnica explicitamente assumida, não se liberta o professor nem o incentiva à autonomia curricular.

Em suma, a despeito das recorrentes críticas aos modelos de formação pautados nos pressupostos técnicos e práticos tecidas pordiferentes pesquisas na área de formação de professores, essas concepções marcam presença nos documentos curriculares analisados, ainda que em diferentes tonalidades. Contudo, o fato de nenhum dos documentos se assumir como puramente técnico e pender mais para a epistemologia da prática, é considerado, pelas mesmas pesquisas, como avanço (DUARTE et al., 2009). Esse avanço pode ser compreendido como possibilidade de mudanças e representar contribuições para a construção de outros modelos formativos que privilegiem a formação do professor reflexivo e crítico em contínua construção de sua docência como práxis pedagógica. 


\section{The Training and Role of Science Teachers in the Curricular Framework: The Position of Official Documents}

Abstract: This paper discusses teacher training concepts and the role of teachers in face of the prescribed curriculum from the perspective of curricular documents for the discipline of sciences in six Brazilian states. The analysis was mediated by categories based on teacher education models (i.e., the categories of technical rationality, epistemology of practice, and epistemology of critique) and the roles that the teacher can take on: maintenance-imitation, curriculum mediator, and creative-generator (SACRISTÁN, 1991). Results indicate the coexistence of the technical and practical models, and timid signs of the critical model, with a predominant orientation towards the practical teacher, which is consistent with a more pronounced prediction of the teacher as a curriculum mediator. We conclude that these results reflect advances representing possible changes towards a teacher education that privileges the reflective/critical teacher and the construction of teaching as a praxis.

Keywords: Teacher education, formative models, teaching role, curriculum guidelines. 


\section{La formación y el papel del profesor de Ciencias en la construcción curricular: la visión de los documentos oficiales}

Resumen: Este trabajo trata sobre concepciones de formación docente y el papel del profesor docente delante del currículo prescrito, a partir de la observación de documentos curriculares del área de Ciencias de seis estados brasileños. El análisis se realizó a partir de categorías elaboradas con base en los modelos de formación docente (racionalidad técnica, epistemología de la práctica y de la crítica) y en los papeles que el profesor puede asumir: mantenimiento-imitación, mediador curricular y creativogenerador (SACRISTÁN, 1991). Los resultados indican la coexistencia de los modelos técnico y práctico, y tímidos indicios del crítico, con predominio de la formación del profesor práctico, coherente con la previsión más acentuada del profesor como mediador curricular. Se llega a la conclusión de que estos resultados significan avances representativos de posibles cambios en favor de la formación del profesor reflexivo/crítico y de la construcción de la docencia como praxis.

Palabras clave: Formación de profesores. Modelos formativos. Papel docente. Orientaciones curriculares. 


\section{REFERÊNCIAS}

ABIB, M. L. V. S. A pesquisa em ensino de física e a sala de aula: articulações necessárias na formação de professores. In: GARCIA, R. et al. A pesquisa em ensino de física e a sala de aula: articulações necessárias. In: ENCONTRO DE PESQUISA EM ENSINO DE FÍSICA, 11, 2010, Curitiba. Anais... Curitiba, 2010.

ACRE. Orientações Curriculares para o Ensino Fundamental: Caderno 1 Ciências Naturais. Rio Branco: SEE, 2010.

ALARCÃO, I. Professores reflexivos em uma escola reflexiva. São Paulo: Cortez, 2005.

ARRUDA, A. M. S. Professores formadores: formação, concepção e ações. 1995. Dissertação (Mestrado em Educação)-Faculdade de Educação, Universidade de São Paulo, São Paulo, 2004.

AZEVEDO, M. N. Ensinar ciências e pesquisa-ação: saberes docentes em elaboração. Jundiaí: Paco Editorial, 2013.

CANAVARRO, A. P.; PONTE, J. P. O papel do professor no currículo de matemática. In: GTI (Ed.) 0 professor e o desenvolvimento curricular. Lisboa: APM, 2005. p. 63-89. Disponível em: 〈http://repositorio.ul.pt/bitstream/10451/4085/1/05Canavarro-Ponte\%28GTI\%29.pdf〉. Acesso em: 18 nov. 2015.

CARVALHO, A. M.; GIL-PÉREZ, D. Formação de professores de ciências: tendências e inovações. São Paulo: Cortez, 2001.

CONTRERAS, J. A autonomia de professores. São Paulo: Cortez, 2002.

DINIZ-PEREIRA, J. A pesquisa dos educadores como estratégia para construção de modelos críticos de formação docente. In: DINIZ-PEREIRA, J. E. D.; ZEICHNER, K. M (Org.). A pesquisa na formação e no trabalho docente. Belo Horizonte: Autêntica, 2002.

DUARTE, M. S.; SHWARTZ, L. B.; SILVA, A. M. T. B.; REZENDE, F. Perspectivas para além da racionalidade técnica para além da formação de professores de ciências. In: ENCONTRO NACIONAL DE PESQUISAS EM ENSINO DE CIÊNCIAS, 7, 2009, Florianópolis. Anais... Florianópolis, 2009. Disponível em:

〈http://posgrad.fae.ufmg.br/posgrad/viienpec/pdfs/novo_07.pdf〉. Acesso em: 10 nov. 2015. 
GHEDIN, E. Professor reflexivo: da alienação à autonomia da crítica. In: PIMENTA, S. G.; GHEDIN, E. (Org.). Professor reflexivo no Brasil: gênese e crítica de um conceito. São Paulo: Cortez, 2002.

MARANDINO, M. A prática de ensino nas licenciaturas e a pesquisa em ensino de Ciências: questões atuais. Caderno Brasileiro do Ensino de Física, v. 20, n. 2, p. 168-193, ago. 2003.

MATO GROSSO. Orientações Curriculares: Área de Ciências da Natureza e Matemática: Educação Básica. Cuiabá: Seduc-MT, 2010.

MIZUKAMI, M. G. N. Ensino: as abordagens do processo. São Paulo: EPU, 1986.

MORGADO, J. C. Identidade e profissionalidade docente: sentidos e (in) possibilidades. Ensaio - Avaliação e Políticas Públicas em Educação, Rio de Janeiro, v. 19, n. 73, p. 793-812, out./dez. 2011.

PARANÁ. Diretrizes Curriculares da Educação Básica: Ciências. Curitiba: Seep, 2008.

PÉREZ GÓMEZ, A. I. A função e formação do/a professor/a no ensino para a compreensão: diferentes perspectivas. In: SACRISTÁN, J. G.; PÉREZ GÓMEZ, A. I. (Org.). Compreender e transformar o ensino. Porto Alegre: Artmed, 2000.

PERNAMBUCO. Parâmetros Curriculares de Ciências Naturais - Ensino Fundamental. Recife: Seep, $2013 a$.

Parâmetros na sala de aula - Ciências Naturais $6^{0}$ ao $9^{0}$ ano do Ensino Fundamental. Recife: Seep, 2013b.

. Parâmetros de formação docente para o Ensino de Ciências Naturais, Biologia, Física, Química e Matemática. Pernambuco: Seep, 2014.

PIMENTA, S. G. Professor reflexivo: construindo uma crítica. In: PIMENTA, S. G.; GHEDIN, E. (Org.). Professor reflexivo no Brasil: gênese e crítica de um conceito. São Paulo: Cortez, 2002.

RODRIGUES, M. I. R. Professores-pesquisadores: reflexão e a mudança metodológica no ensino da termodinâmica. 2001. Dissertação (Mestrado em Educação)-Faculdade de Educação, Universidade de São Paulo, São Paulo, 2001.

SACRISTÁN, J. G. El curriculum: una reflexión sobre la práctica. Madri: Ediciones Morata, 1991. 
. O currículo: os conteúdos do ensino ou uma análise da prática? In: SACRISTÁN, J. G.; PÉREZ GÓMEZ, A. I. (Org.). Compreender e transformar o ensino. Porto Alegre: Artmed, 2000.

SÃO PAULO. Ciências da Natureza e suas Tecnologias: Ensino Fundamental Ciclo Il e Ensino Médio. São Paulo: Sesp, 2012.

. Material de Apoio ao Currículo do Estado de São Paulo: Caderno do Professor Ciências Ensino Fundamental - Anos finais 5a série/6 ano - Volume 1. São Paulo: 2014/2017.

SAVIANI, D. Pedagogia histórico-crítica: primeiras aproximações. Campinas: Autores Associados, 2003.

SCHÖN, D. Formar professores como profissionais reflexivos. In: NÓVOA, António (Org.) Os professores e sua formação. Lisboa: Dom Quixote, 1992.

TESTONI, L. A.; ABIB, M. L. V. S. Caminhos criativos na formação inicial do professor de física. Jundiaí: Paco Editorial, 2014.

VILLANI, A.; FREITAS, D. Formação de professores de ciências: um desafio sem limites. Investigações em Ensino de Ciências, v. 7, n. 3, p. 215-230, set. 2002.

\section{Sobre os autores:}

Maria Nizete de Azevedo é doutora em Ensino de Ciências. Professora Adjunta e Pesquisadora na Universidade Federal de São Paulo (UNIFESP).

maria.nizete@unifesp.br

Leonardo André Testoni é doutor em Ensino de Ciências e Matemática. Professor Adjunto e Pesquisador na Universidade Federal de São Paulo (UNIFESP)

leonardo.testoni@unifesp.br

Recebido em: novembro de 2015

Aprovado em: fevereiro de 2016 